\title{
CD14 knockdown reduces lipopolysaccharide-induced cell viability and expression of inflammation-associated genes in gastric cancer cells in vitro and in nude mouse xenografts
}

\author{
KANG LI ${ }^{1,2^{*}}$, ZENG DAN $^{1 *}$, YUQIANG NIE ${ }^{3}$ XUEJUN HU ${ }^{1 *}$, LUOBU GESANG $^{1 *}$, \\ ZHAXI BIANBA ${ }^{2}$, YONGGE ZE $^{2}$ and CUOMU CIREN ${ }^{2}$
}

\begin{abstract}
Departments of ${ }^{1}$ Gastroenterology and ${ }^{2}$ Oncology, People's Hospital of Tibet Autonomous Region, Lhasa, Tibet Autonomous Region 850000; ${ }^{3}$ Department of Gastroenterology, Guangzhou First People's Hospital, Guangzhou Medical University, Guangzhou, Guangdong 510180, P.R. China
\end{abstract}

Received June 26, 2014; Accepted March 16, 2015

DOI: $10.3892 / \mathrm{mmr} .2015 .3924$

\begin{abstract}
The present study examined the role of CD14 in the regulation of lipopolysaccharide (LPS)-induced effects on gastric cancer cells. MGC-803 cells were stably transfected with CD14 short hairpin (sh)RNA and treated with LPS, followed by assessment of cell proliferation, apoptosis and gene expression using a cell counting kit- 8 assay, flow cytometry, reverse transcription-polymerase chain reaction and western blot analysis, respectively. The cells subjected to CD14 knockdown were treated with $10 \mathrm{~g} / \mathrm{ml}$ LPS and injected into nude mice to form tumor xenografts. CD14 shRNA-transfected MGC-803 cells did not exhibit any significant changes in cell viability compared with the control cells $(\mathrm{P}>0.05)$, but cell viability was markedly increased in the wild-type (WT) + LPS group $(\mathrm{P}<0.05)$. In contrast to the WT + LPS group, the cell viability of the sh-CD14 + LPS group was markedly decreased $(\mathrm{P}<0.05)$. In addition, compared with those in the controls, the level of sh-CD14 cell apoptosis did not change significantly; however, it was markedly reduced in the LPS group. Compared with that in the WT + LPS group, the rate of apoptosis in the sh-CD14 + LPS group increased to a certain extent, while it remained lower in the control group. In addition, compared with that in the control, the expression of tumor necrosis factor- $\alpha$, interleukin (IL)-1, IL-6 and IL-12, and human $\beta$-defensin 2 was significantly increased in the WT + LPS group, while, compared with that in the WT + LPS group, the expression of these genes was markedly reduced in
\end{abstract}

Correspondence to: Dr Kang Li, Department of Gastroenterology, People's Hospital of Tibet Autonomous Region, 18 North Lin Kuo Road, Lhasa, Tibet Autonomous Region 850000, P.R. China E-mail: 807751243@qq.com

*Contributed equally

Key words: cluster of differentiation 14, lipopolysaccharide, gastric cancer, inflammatory responsible genes, tumor xenograft the sh-CD14 + LPS group $(\mathrm{P}<0.05)$. The nude mouse experiments further confirmed the in vitro data, including the finding that LPS promoted the growth of xenografts, but knockdown of CD14 expression reduced the response of tumor cells to LPS treatment. In conclusion, LPS induced cell viability and the release of inflammatory cytokines, but inhibited gastric cancer cell apoptosis. Knockdown of CD14 expression had no significant effect on gastric cancer malignancy, but mediated LPS signal transduction.

\section{Introduction}

Gastric cancer is one of the most common types of cancer globally and accounted for 989,600 ovel cases and 738,000 cancer-associated fatalities in 2008 (1). $>70 \%$ of novel gastric cancer cases and fatalities occur in the developing countries, while they have declined in the majority of developed countries, including countries in North America and Europe in previous decades (1). The risk factors for gastric cancer include Helicobacter (H.) pylori infection, history of tobacco smoking, and consumption of smoked foods, salted meat or fish and pickled vegetables. However, intake of fresh fruits and vegetables appears to lower the risk of gastric cancer (1). Regional variations in gastric cancer prevalence reflect the differences in dietary patterns and the prevalence of $H$. pylori infection (2). H. pylori is an aerobic Gram-negative bacterium found in the stomach, which causes chronic gastritis, peptic ulcers and gastric cancer. Thus, $H$. pylori infection has been classified as a class I carcinogen for gastric cancer and gastric mucosa-associated lymphoid tissue lymphoma (3). Lipopolysaccharide (LPS) is the main component of Gram-negative bacterial endotoxin and elicits marked immune responses in the host by binding to the CD14/Toll-like receptor (TLR)4/MD2 receptor complex, which promotes the secretion of pro-inflammatory cytokines in numerous cell types. Of note, CD14 is a high-affinity receptor for LPS and recognizes Gram-negative bacteria, fungi, Mycobacterium tuberculosis and Treponema pallidum, mediating a series of inflammatory responses in the human body $(4,5)$. 
CD14 is mainly expressed in macrophages and in neutrophil granulocytes. Upon $H$. pylori infection, LPS may bind to CD14 and activate the immune defense system in the human body and induce the production of cytokines to trigger inflammation (6). Furthermore, CD14 has also been reported to be abnormally expressed in different cancer tissues and cells $(7,8)$. However, it remains to be defined how altered CD14 expression induces gastric cancer development following H. pylori infection. Thus, in the present study, the effects of knockdown of CD14 in the regulation of gastric cancer cell viability, apoptosis and the inflammatory response induced by LPS were investigated, as well as the underlying mechanism in vitro and in nude mouse gastric cancer cell xenografts. The present study provided novel insight regarding the mediation of $H$. pylori infection via CD14 in the induction of gastric cancer in humans.

\section{Materials and methods}

Cell lines and culture. The MGC-803 human gastric cancer cell line was obtained from the Type Culture Collection Center of Chinese Academy of Science (Shanghai, China) and the sh-CD14 stable CD14-knockdown MGC-803 cell subline was constructed in our previous study (9). The cells were stored in the laboratory and cultured with RPMI-1640 medium supplemented with $10 \%$ fetal bovine serum (Thermo Fisher Scientific Inc., Waltham, MA, USA), $100 \mathrm{U} / \mathrm{ml}$ penicillin and $100 \mathrm{mg} / \mathrm{l}$ streptomycin (Beijing Solarbio Science \& Technology Co., Ltd., Beijing, China) in a humidified incubator with $5 \% \mathrm{CO}_{2}$ at $37^{\circ} \mathrm{C}$. The cells were passaged using $0.05 \%$ trypsin-EDTA (Beyotime Institute of Biotechnology, Haimen, China) every 2-3 days and the cells at the logarithmic phase were used in the present study. The cells were treated with $1 \mu \mathrm{g} / \mathrm{ml}$ LPS (Sigma-Aldrich, St. Louis, MO, USA) for $4 \mathrm{~h}$ and harvested for in vitro study, and treated with $10 \mu \mathrm{g} / \mathrm{ml}$ LPS for $16 \mathrm{~h}$ for the tumor xenograft assay. Cells were divided into the following groups: Wild-type (WT) cells (MGC-803 cells without any interference), sh-CD14 cells (MGC-803 cells subjected to stable CD14-knockdown), WT + LPS cells (MGC-803 cells treated with $1 \mu \mathrm{g} / \mathrm{ml}$ LPS for $4 \mathrm{~h}$ or $10 \mu \mathrm{g} / \mathrm{ml}$ LPS for $16 \mathrm{~h}$ ) and the LPS + sh-CD14 group (MGC-803 cells subjected to stable CD14-knockdown treated with $1 \mu \mathrm{g} / \mathrm{ml}$ LPS for $4 \mathrm{~h}$ or $10 \mu \mathrm{g} / \mathrm{ml}$ LPS for $16 \mathrm{~h}$ ). The present study was approved by the Institutional Review Board of the People's Hospital of Tibet Autonomous Region (Tibet, China).

Cell counting kit-8 (CCK-8) assay. To assess the cell viability, a CCK-8 assay was performed. Briefly, the cells were detached from cell culture dishes, counted and diluted to a concentration of $5.0 \times 10^{4}$ cells $/ \mathrm{ml}$ in a single-cell suspension and then seeded into a 96 -well plate at $5.0 \times 10^{3}$ cells/well. The cells were cultured and then treated as stated above, dependent on their assigned group. At the end of each experiment, $10 \mu$ CCK-8 reagent (Beyotime Institute of Biotechnology) was added into each well and incubated at $37^{\circ} \mathrm{C}$ for $1 \mathrm{~h}$, and the optical density was assessed using a microplate reader (Microplate Autoreader EL311; Bio-Tek Instruments, Inc., Winooski, VT, USA) at $450 \mathrm{~nm}$. The experiments were performed in duplicates of five wells for each group and repeated three times.
Nude mouse gastric cancer cell xenograft assay. Nude mice were purchased from the Experimental Animal Center, China Medical University (Shenyang, China). Each group of cells was detached from the cell culture dishes, counted and adjusted to a concentration of $2 \times 10^{7}$ cells $/ \mathrm{ml}$, then $0.2 \mathrm{ml}$ cell suspension was injected into the axilla of each nude mouse. The tumor formation was recorded by measuring the maximum vertical diameters of the length (a) and width (b) every three days. The tumor volume was calculated using the following formula: $\mathrm{V}\left(\mathrm{mm}^{3}\right)=0.5 \mathrm{x} \mathrm{a} \mathrm{x}^{2}$. The growth curve of the tumor was plotted. After four weeks, the nude mice were sacrificed by intraperitoneal injection of $10 \%$ chloral hydrate (Sinopharm Chemical Reagent Co., Ltd., Shanghai, China), and the final volume and weight of the tumor xenografts were recorded. One half of each of the xenograft tumors was fixed in $4 \%$ paraformaldehyde, embedded in paraffin and sectioned into $5-\mu \mathrm{m}$ tissue sections for hematoxylin and eosin (H\&E) staining (Beijing Solarbio Science \& Technology Co., Ltd.). The remaining half of the tumor was immediately frozen in liquid nitrogen and stored at $-80^{\circ} \mathrm{C}$ until further use.

Flow cytometric cell apoptosis assays. To detect changes in the levels of cell apoptosis in vitro, the Annexin V/propidium iodide (AV/PI) apoptosis detection kit (KeyGen Biotech, Nanjing, China) was used according to the manufacturer's instructions. Briefly, the cells were centrifuged at $1,000 \mathrm{x} \mathrm{g}$ for $5 \mathrm{~min}$ and the supernatant was discarded. Subsequently, $500 \mu \mathrm{l}$ binding buffer was added into the tube to re-suspend the cells and $5 \mu \mathrm{l}$ Annexin V-fluorescein isothiocyanate and propidium iodide were added. The cells were then incubated at room temperature in the dark for $10 \mathrm{~min}$ and subjected to flow cytometry (FACSCalibur; BD Biosciences, Mountain View, CA, USA) at a wavelength of $488 \mathrm{~nm}$ and an output power of $100 \mathrm{~mW}$. The data were analyzed using the software included in the machine package (Cell Quest; BD Biosciences).

RNA isolation and reverse transcription-polymerase chain reaction $(R T-P C R)$. Total cellular RNA was isolated using TRIzol reagent (Tiangen Biotech, Beijing, China) according to the manufacturer's instructions and reverse transcribed into cDNA using a TianScript cDNA first strand cDNA synthesis kit (Tiangen Biotech) according to the manufacturer's instructions. The reaction mix consisted of $1 \mu \mathrm{g}$ total RNA, $1 \mu \mathrm{l}$ oligo $(\mathrm{dT})_{15}$ and random primer, $2 \mu \mathrm{l}$ deoxyribunucleotide triphosphate and $2 \mu \mathrm{l}$ double distilled (dd) $\mathrm{H}_{2} \mathrm{O}$ with a total volume of $14.5 \mu \mathrm{l}$. Following denaturation at $70^{\circ} \mathrm{C}$ for $5 \mathrm{~min}$, the mixture was placed on ice immediately. Following a short vortex spin, $0.5 \mu 1$ RNasin (Tiangen Biotech) and $1 \mu \mathrm{l}$ Moloney murine leukemia virus reverse transcriptase (Bioteke Corporation, Beijing, China) were added into the mixture for incubation at $42^{\circ} \mathrm{C}$ for $50 \mathrm{~min}$. To terminate the reaction, the reaction mixture was heated at $95^{\circ} \mathrm{C}$ for $5 \mathrm{~min}$. The primers used for RT-PCR are shown in Table I. The PCR amplification was performed with a $1 \mu \mathrm{l}$ DNA template, $1 \mu \mathrm{l}$ of each primer, $10 \mu \mathrm{l} 2 \mathrm{X}$ Taq PCR master-mix (Tiangen Biotech) and $8 \mu \mathrm{lddH_{2 }}$ O. The PCR cycles were set at an initial $95^{\circ} \mathrm{C}$ for $5 \mathrm{~min}$ and 30 cycles of $95^{\circ} \mathrm{C}$ for $20 \mathrm{sec}, 58^{\circ} \mathrm{C}$ for $20 \mathrm{sec}$ and $72^{\circ} \mathrm{C}$ for $30 \mathrm{sec}$, followed by a final step at $72^{\circ} \mathrm{C}$ for $5 \mathrm{~min}$. The PCR products were separated by electrophoresis on $1 \%$ agarose gels (Biowest, Madrid, Spain), images were captured and levels of $\beta$-actin expression were 
Table I. Primers used for reverse transcription-polymerase chain reaction.

\begin{tabular}{|c|c|c|}
\hline Gene & Sequences & Size (bp \\
\hline TNF- $\alpha$ & $\begin{array}{l}\text { 5'-GTCTCCTACCAGACCAAGGTCAAC-3' } \\
\text { 5'-CACAGGGCAATGATCCCAAAGTAG-3' }\end{array}$ & 221 \\
\hline IL-1 $\beta$ & $\begin{array}{l}\text { 5'-CCTGGACTTTCCTGTTGTCTACACC-3' } \\
\text { 5'-TCTGTCAGGCGGGCTTTAAGTGAG-3' }\end{array}$ & 178 \\
\hline IL-6 & $\begin{array}{l}\text { 5'-TCACCTCTTCAGAACGAATTGACA-3' } \\
\text { 5'-AGTGCCTCTTTGCTGCTTTCACAC-3' }\end{array}$ & 115 \\
\hline IL-12 & $\begin{array}{l}\text { 5'-AGATGGTATCACCTGGACCTTGGAC-3' } \\
\text { 5'-ATGGCTTAGAACCTCGCCTCCTTTG-3' }\end{array}$ & 133 \\
\hline hBD-2 & $\begin{array}{l}\text { 5'-CCTCTTCATATTCCTGATGCCTCT-3' } \\
\text { 5'-GGTGCCAATTTGTTTATACCTTCTAG-3' }\end{array}$ & 127 \\
\hline TLR4 & $\begin{array}{l}\text { 5'-CTTTAGACCTGTCCCTGAACC-3' } \\
\text { 5'-CCAGAACCAAACGATGGACTT-3' }\end{array}$ & 162 \\
\hline $\mathrm{h} \beta$-actin & $\begin{array}{l}\text { 5'-CTTAGTTGCGTTACACCCTTTCTTG-3' } \\
\text { 5'-CTGTCACCTTCACCGTTCCAGTTT-3' }\end{array}$ & 156 \\
\hline
\end{tabular}

TNF, tumor necrosis factor; IL, interleukin; hBD-2, human $\beta$-defensin 2; TLR4, Toll-like receptor 4.

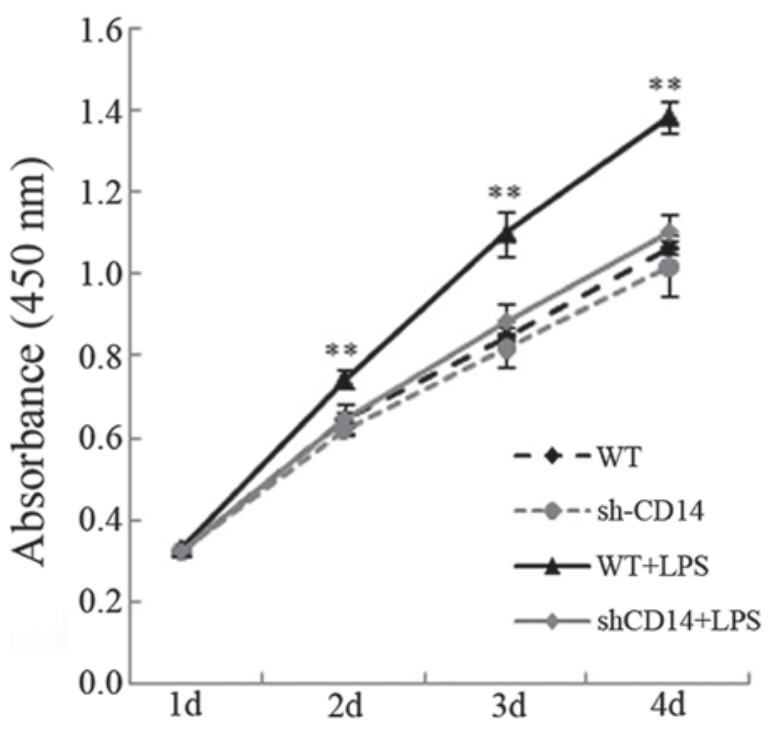

Figure 1. Effects of CD14 knockdown on regulation of gastric cancer cell viability. All cell groups were grown for four days and subjected to a cell counting kit- 8 assay. The experiments were set to five wells of each setting and repeated three times. Values are expressed as the mean \pm standard deviation $(\mathrm{n}=6) .{ }^{* *} \mathrm{P}<0.05$, compared with WT group cells. LPS, lipopolysaccharide; WT, wild-type.

used as the internal control for gray scale analysis (Gel Image System version 4.0; Tanon Science \& Technology, Shanghai, China).

Protein extraction and western blot analysis. Total cellular protein was extracted with a radioimmunoprecipitation assay lysis buffer (Beyotime Institute of Biotechnology) and the concentration of these protein samples was quantified using the bicinchoninic acid method (Beyotime Institute of Biotechnology). Protein lysates with $40 \mu \mathrm{g}$ protein were separated by SDS-PAGE and transferred onto polyvinylidene difluoride membranes (Millipore, Boston, MA, USA). Following blocking with $5 \%$ fat-free milk for $1 \mathrm{~h}$, the membranes were incubated with diluted primary antibodies at $4^{\circ} \mathrm{C}$ overnight. Rabbit polyclonal anti-human $\beta$-defensin 2 (hBD-2; cat. no. sc-20798) was used at a dilution of 1:2,000, rabbit polyclonal anti-TLR4 (cat. no. sc-10741) was used at 1:100 (Santa Cruz Biotechnology, Inc., Dallas, TX, USA), rabbit polyclonal anti-tumor necrosis factor- $\alpha$ (TNF- $\alpha$; cat. no. bs-0078R) was used at 1:500, rabbit polyclonal anti-interleukin (IL)-1 $\beta$ (cat. no. bs-0812R) was used at 1:800, rabbit polyclonal anti-IL-6 (cat. no. bs-0379R) was used at 1:800 and rabbit polyclonal IL-12 (cat. no. bs-10641R) was used at 1:500 (Bioss, Beijing, China). Following an overnight incubation, the membranes were washed with Tris-buffered saline-Tween 20 (TBS-T; Beijing Solarbio Science \& Technology Co., Ltd.) three times and then further incubated with a horseradish peroxidase-labeled goat anti-rabbit secondary antibody (cat. no. A0208; Beyotime Institute of Biotechnology) at a dilution of 1:1,000 for $1 \mathrm{~h}$. The membranes were then washed again with TBS-T and incubated with enhanced chemiluminescence solution (Pierce Biotechnology, Inc., Rockford, IL, USA) for up to $5 \mathrm{~min}$ to develop a color reaction in the dark against an X-ray film (Fujifilm, Shanghai, China). The antibody on the membrane was stripped using stripping buffer (Beyotime Institute of Biotechnology) and the membranes were re-blotted with rabbit polyclonal anti- $\beta$-actin antibody (1:1,000 dilution; cat. no. WL0001; Wanleibio, Shenyang, China) as an internal antibody using the same procedure.

Statistical analysis. Values are presented as the mean \pm standard error of the mean and Student's t-test was performed to compare the data between the experimental group and the controls. $\mathrm{P}<0.05$ was considered to indicate a statistically significant difference. SPSS 16.0 software (SPSS, Inc., Chicago, IL, USA) was used to analyze the data. 
A

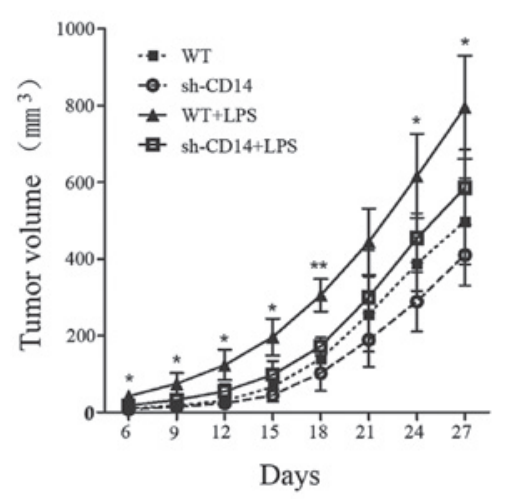

C

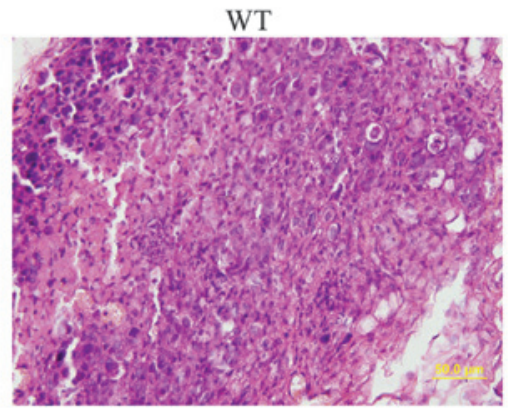

sh-CD14

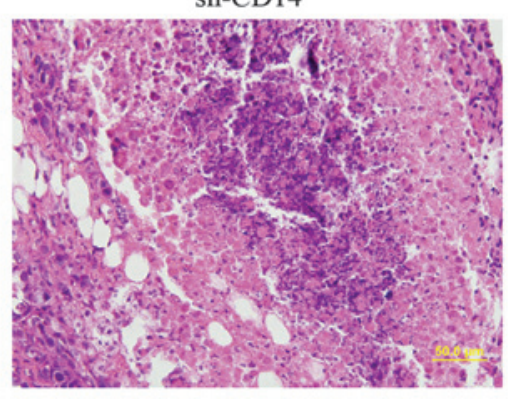

B

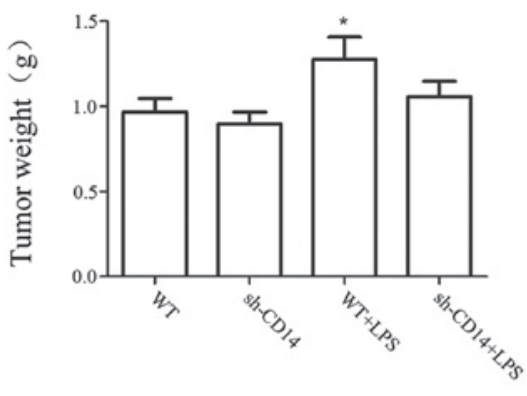

WT+LPS

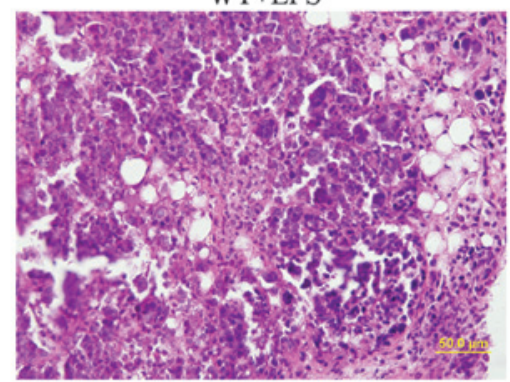

sh-CD14+LPS

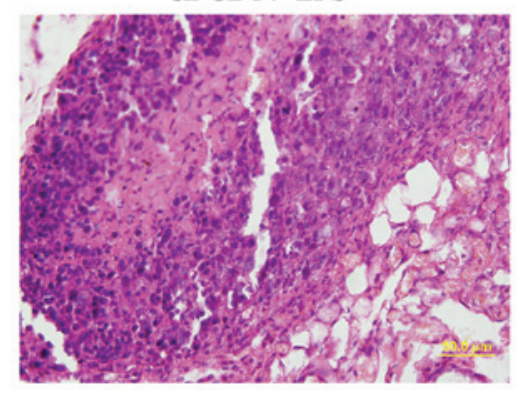

Figure 2. Effects of CD14 knockdown on regulation of gastric cancer cell xenograft formation. WT cells and CD14 shRNA-transfected gastric cancer cells were treated with or without $10 \mu \mathrm{g} / \mathrm{ml}$ LPS for $16 \mathrm{~h}$ and then injected into six nude mice for observation of xenograft formation for four weeks. (A) Tumor volume and (B) tumor weight are shown. Values are expressed as the mean \pm standard deviation $(n=6)$. $(C)$ Subsequently, the xenografts were removed for tissue processing and hematoxylin and eosin staining (scale bar, $50 \mu \mathrm{M}$ ). ${ }^{*} \mathrm{P}<0.05$ on day 27 compared with the WT group. LPS, lipopolysaccharide; WT, wild-type; sh, short hairpin.

\section{Results}

Effects of CD14 knockdown on regulation of gastric cancer cell viability. In the present study, the effects of CD14 knockdown were initially assessed with regard to the regulation of gastric cancer cell viability. As compared with the WT group, the cell viability of the LPS cells was significantly increased $(\mathrm{P}<0.05)$, whereas viability of the stable CD14-knockdown cells exhibited a slight increase in viability $(\mathrm{P}<0.05)$, even following LPS treatment $(\mathrm{P}>0.05$; Fig. 1). The results suggested that $\mathrm{CD} 14$ is important in preserving cell viability following treatment with LPS.

Effects of CD14 knockdown on regulation of gastric cancer cell xenograft tumor growth. The volume of tumors was measured to examine the effect of CD14 knockdown on the growth of tumor xenografts (Fig. 2A). Compared with the WT group, no significant difference was identified in the tumor volume in the sh-CD14 group $(\mathrm{P}>0.05)$. By contrast, the tumor volume was markedly increased in the LPS group. However, from day 21 , the growth of the tumors gradually slowed down in the sh-CD14 + LPS group, while tumors remained slightly larger than in the WT group, although no statistically significant difference was identified $(\mathrm{P}>0.05)$. On day 27 of the experiment, the tumor xenograft tissues were collected and weighed (Fig. 2B). The results revealed that the tumor mass in the WT + LPS group was significantly higher than that in the WT group $(\mathrm{P}<0.05)$. However, no statistically significant differences were identified between the WT group and the sh-CD14 and sh-CD14 + LPS groups ( $\mathrm{P}>0.05$ for the two groups). H\&E staining revealed that the nucleoplasm was larger in the WT + LPS group, exhibiting active cell division and proliferation (Fig. 2C). However, tumor xenograft formation and growth of the sh-CD14 and sh-CD14 + LPS groups were similar, but obviously different from those in the WT group, indicating that LPS may promote the growth of tumor xenografts; however, CD14 had a non-negligible role in mediating LPS signal transduction.

Effects of CD14 knockdown on regulation of cell apoptosis in gastric cancer cell xenograft tumors. Following 

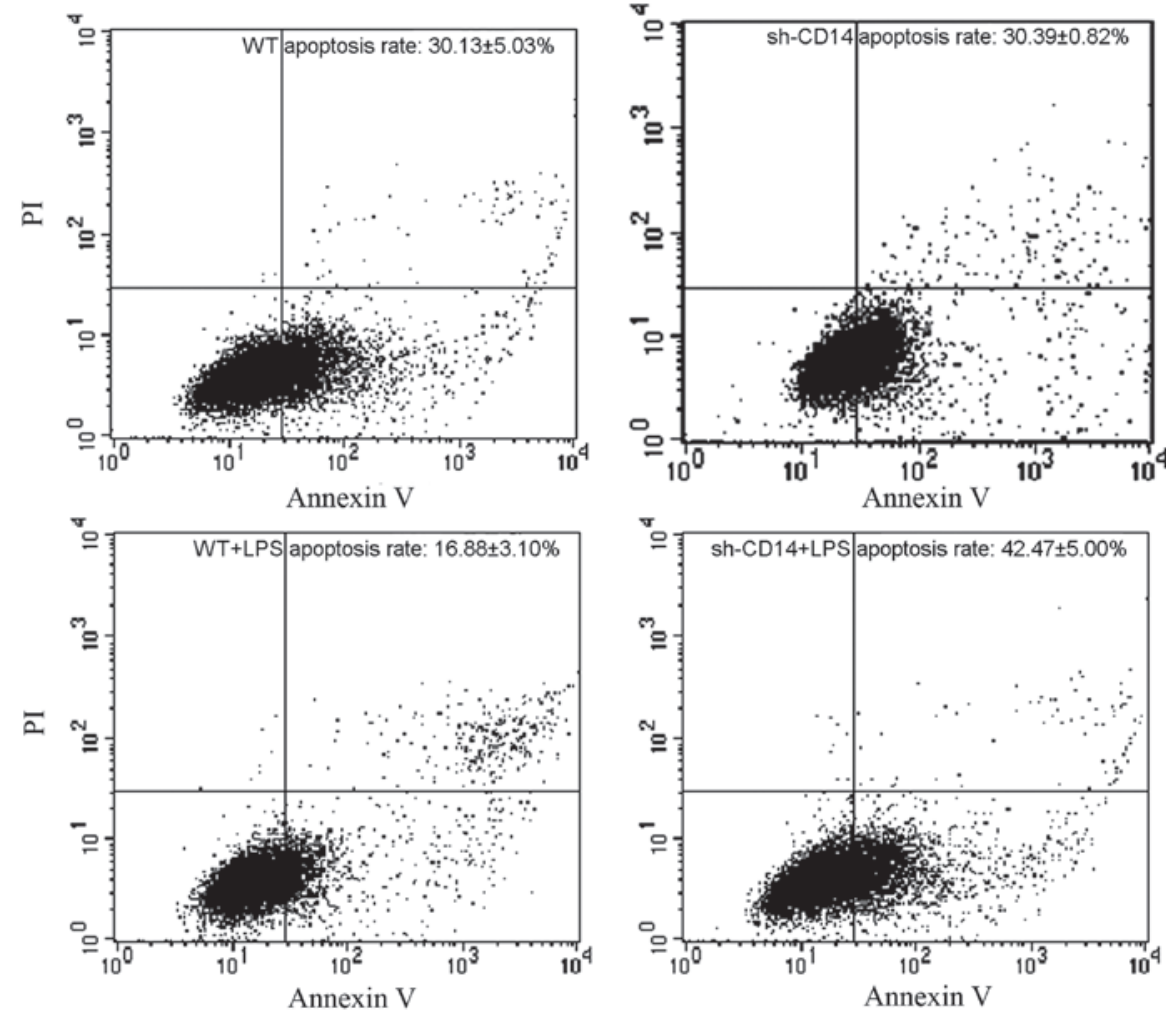

Figure 3. Effects of CD14 knockdown on regulation of apoptosis. Flow cytometric analysis of apoptosis in vitro. Values are presented as the mean \pm standard deviation. LPS, lipopolysaccharide; WT, wild-type; sh, small hairpin; PI, propidium iodide.

A

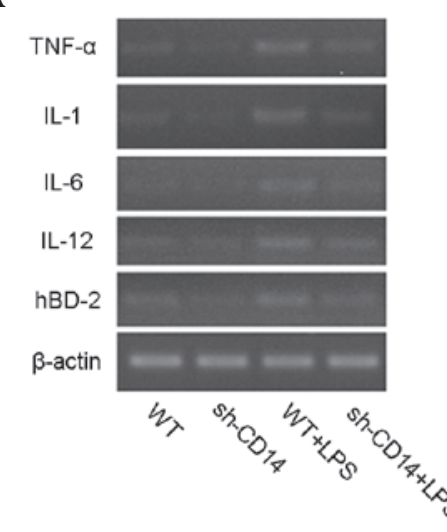

C

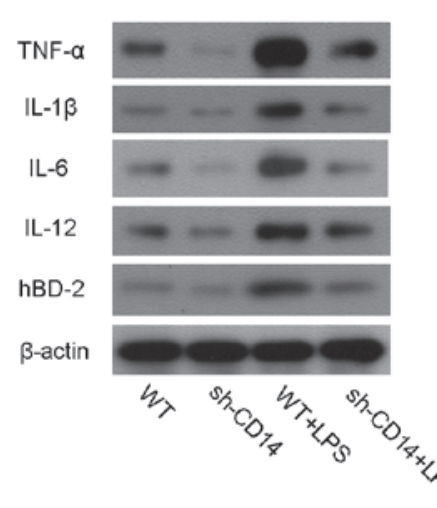

B

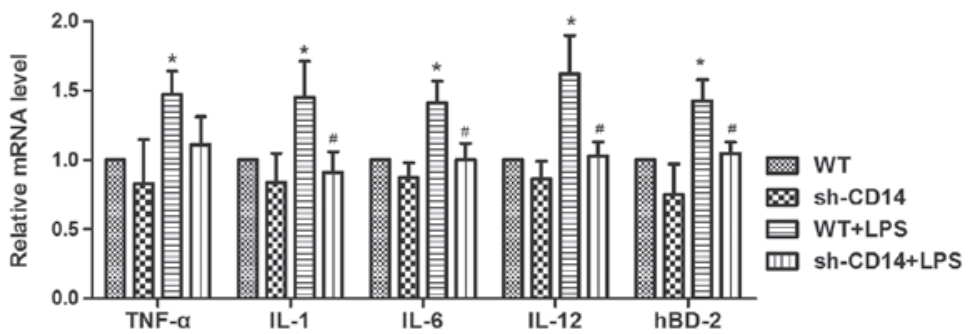

D

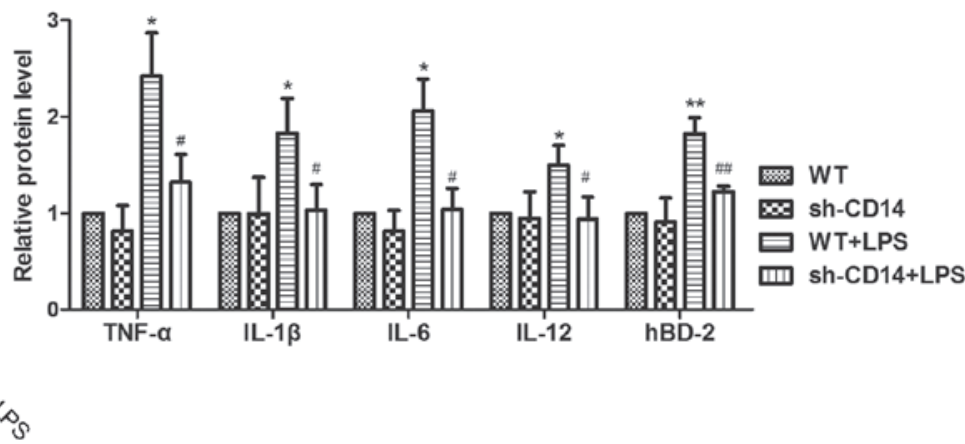

Figure 4. Effects of CD14 knockdown on regulation of inflammatory gene expression in gastric cancer cell xenografts. (A) Quantitative polymerase chain reaction analysis of inflammatory gene expression; (B) quantified results of A. (C) Western blot analysis of protein expression of inflammatory genes; (D) quantified results of $\mathrm{C}$. Values are expressed as the mean \pm standard deviation $(\mathrm{n}=3)$. ${ }^{*} \mathrm{P}<0.05$ and ${ }^{* *} \mathrm{P}<0.01$, compared with the WT group. ${ }^{\#} \mathrm{P}<0.05$, compared with the $\mathrm{LPS}$ group. LPS, lipopolysaccharide; WT, wild-type; TNF, tumor necrosis factor; IL, interleukin; hBD-2, human $\beta$-defensin 2; sh, small hairpin. 
A

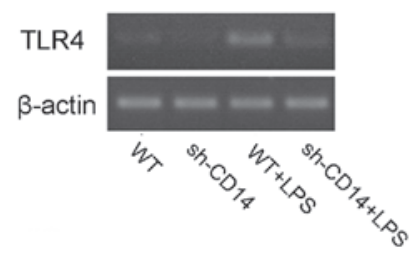

B

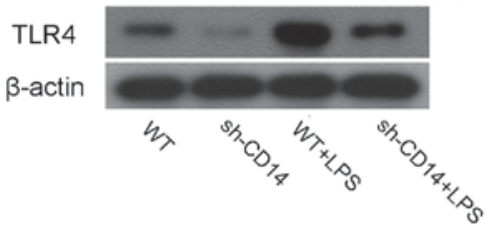

C

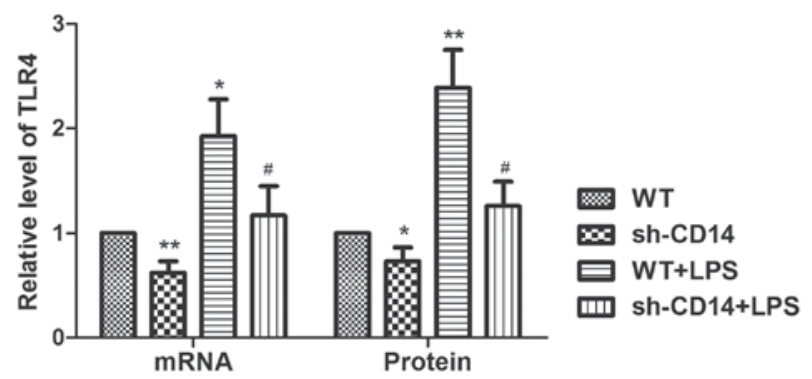

Figure 5. Effect of CD14 knockdown on expression of TLR4 mRNA and protein. (A) Reverse transcription-polymerase chain reaction; (B) Western blot analysis; (C) quantification of A and B. Values are expressed as the mean \pm standard deviation $(\mathrm{n}=3)$. ${ }^{* *} \mathrm{P}<0.01$ and ${ }^{*} \mathrm{P}<0.05$, compared with the WT group. ${ }^{\#} \mathrm{P}<0.05$ compared with the LPS group. LPS, lipopolysaccharide; WT, wildtype; TLR4, Toll-like receptor 4; sh, small hairpin.

Annexin V/propidium iodide staining, the apoptotic rate in each group was determined using flow cytometry (Fig. 3). Compared with the control group $(30.13 \pm 5.03 \%)$, no significant differences were identified in the apoptotic rate in the sh-CD14 group $(30.39 \pm 0.82 \%)$; however, the rate was markedly reduced in the LPS group $(16.88 \pm 3.10 \%)$. In contrast to that in the WT + LPS group, the apoptotic rate was increased in the sh-CD14 + LPS group $(42.47 \pm 5.00 \%)$, but it remained lower than that in the control group, suggesting that LPS was able to inhibit the apoptosis of gastric cancer cells, and in addition, CD14 was important in the process of apoptosis.

Effects of CD14 knockdown on regulation of inflammatory gene expression in gastric cancer cell xenografts. The effects of CD14 knockdown on the regulation of inflammatory gene expression in gastric cancer cell xenografts were assessed. The expression of TNF- $\alpha$, IL-1 $\beta$, IL-6, IL-12 and hBD-2 mRNA in each group is shown in Fig. 4. Compared with the WT group, the sh-CD14 group exhibited a decrease in gene expression, but the difference was not statistically significant $(\mathrm{P}>0.05)$. The expression of these genes was induced following LPS treatment in the LPS group $(\mathrm{P}<0.05)$. Compared with the LPS group, there was a decrease in the expression of these genes in the sh-CD14 + LPS group $(\mathrm{P}<0.05)$. The levels of protein expression were in accordance with those of mRNA expression (Fig. 4).

Effect of CD14 knockdown on expression of TLR4. As CD14 binds with TLR4 to form the LPS receptor, the TLR4 expression in the gastric cancer cell xenograft tumors was assessed. Compared with the WT group, the expression of TLR4 mRNA was significantly lower in the sh-CD14 group $(\mathrm{P}<0.05)$. Additionally, compared with the LPS group, the expression of TLR4 mRNA was lower in the sh-CD14 + LPS group $(\mathrm{P}<0.05$; Fig. 5A). The expression levels of TLR4 protein were in accordance with those of mRNA expression (Fig. 5B).

\section{Discussion}

In the present study, the effects of LPS and CD14 on the regulation of gastric cancer cell viability, apoptosis and the expression of inflammation-associated genes were assessed in vitro as well as in vivo in nude mouse xenografts. The data revealed that LPS induced gastric cancer cell proliferation, but inhibited apoptosis and significantly increased the secretion of TNF- $\alpha$, IL-1 $\beta$, IL- 6 , IL-12 and hBD-2 proteins and mRNA. Knockdown of CD14 expression had no marked effect on the rate of proliferation, apoptotic levels and expression of inflammation-associated genes in gastric cancer cells and the xenografts. However, in the presence of LPS, knockdown of CD14 expression markedly reduced the expression of the inflammatory cytokines and hBD-2. These data demonstrated that LPS-promoted growth of gastric cancer cells and tumor xenografts occurred through CD14 expression and the associated signaling pathway.

H. pylori is a Gram-negative bacterium, which is able to selectively infect gastric epithelial cells. It is estimated that half of the world population is infected with H. pylori $(10,11)$. $>80 \%$ of individuals infected with $H$. pylori do not exhibit any symptoms; however, a fraction of them do suffer from acute and chronic gastritis and peptic ulcers, and may eventually develop gastric cancer (12). A growing number of lines of evidence have suggested that $H$. pylori is able to adapt to the local acidic environment and colonize deep in the mucus layer of the gastric epithelium, resulting in chronic gastritis. This host-bacterium interaction may yield persistent chronic infection of $H$. pylori in the stomach and cause harm to the host (13). Previous studies have demonstrated that there is a high expression of CD14 and TLR4 in tissues infected with $H$. pylori, particularly in gastric cancer tissues $(14,15)$. Another study reported that a functional polymorphism of the $C D 14$ promoter was able to affect the expression of CD14 and increase the risk of gastric cancer (16), suggesting that the CD14 protein is important in the transduction of inflam- 
matory signaling and may have an impact on the outcome of the H. pylori infection. The in vitro data from the current study revealed that gastric cancer cell viability was increased following LPS treatment. The knockdown of CD14 expression inhibited LPS treatment-induced gastric cancer cell viability, indicating that CD14 is important in mediating the effects of LPS in gastric cancer cells. CD14 is important in mediating signaling transmission between bacteria and the host. Of note, Grandel et al (17) used LPS to treat A549 non-small cell lung cancer cells and observed that LPS induced tumor cell viability in a time- and dose-dependent manner. However, this effect was inhibited by CD14 and TLR4-neutralizing antibodies. Following stimulation with LPS, gastric cancer cells were grafted subcutaneously into the nude mice to establish a nude mouse xenograft model of gastric cancer. The tumor volume was significantly greater than that of the A549 cells without LPS treatment and expression of the marker of proliferation, $\mathrm{Ki}-67$, in tumor tissues was also significantly increased (18). Similarly, the in vivo data of the present study revealed that following grafting the MGC-803 gastric cancer cell line stimulated by LPS into the axilla of nude mice to establish tumor xenografts, there was an increase in tumor volume and weight in the LPS group, which was consistent with findings of a previous study (17).

LPS is able to induce significant levels of proliferation and inhibit the apoptosis of tumor cells (18). He et al (19) observed that LPS could significantly inhibit apoptosis of gastric cancer cells and that this effect was considered to be closely associated with the activation of TLR4 and its downstream gene, nuclear factor- $\kappa \mathrm{B}(\mathrm{NF}-\kappa \mathrm{B})$. Although CD14 is a high-affinity receptor of LPS, the CD14 protein has neither a transmembrane domain nor a cytoplasmic segment, and therefore, its effect on signal transmission into the nucleus is performed in coordination with TLR4 (20). Baumann et al (21) reported that the level of CD14 protein may affect TLR activity and thus interfere with the effect of certain anti-cancer therapies or anti-viral reactions. In the present study, following LPS treatment, the of apoptotic rate decreased markedly; however, in cells subjected to knockdown of CD14 expression, the inhibitory effect of LPS on apoptosis was blocked. Accordingly, it was hypothesized that LPS may be able to regulate the apoptosis of gastric cancer cells via CD14-TLR4 and its downstream NF- $\kappa B$ signaling pathway, with $\mathrm{CD} 14$ performing a critical role in this process.

It has been widely reported that the CD14/TLR4 signaling pathway is important in cancer cell proliferation and secretion of inflammatory factors. Wang et al (22) found that when CD14 was expressed, LPS induced the expression of $\beta 1$ integrin in colon cancer cells and increased the adhesive ability of tumor cells. In addition, LPS promoted the expression of IL-8 in melanoma cells (23). LPS treatment in ovarian cancer cells significantly promoted the proliferation of tumor cells and the expression of monocyte chemoattractant protein- 1 and IL-6 mRNA (24). The aforementioned studies suggested that LPS is able to affect tumor cell viability and the expression of cancer cell-associated inflammatory factors. hBD-2 is a major component of the innate immune system and a major mediator of the primary defense system of the mucosa and epithelium against microbial invasion. In addition, it is highly expressed during bacterial infection $(25,26)$. In the present study, the secretion of TNF- $\alpha$, IL-1 $\beta$, IL-6, IL-12 and hBD-2 in gastric cancer cells were significantly increased, particularly following LPS treatment. This finding is consistent with that of a previous study (27).

$\mathrm{NF}-\mathrm{\kappa B}$ is an important regulator of inflammation, regulating the expression of numerous types of inflammatory factors, chemokines and anti-apoptotic proteins (28). Thus, NF- $\kappa B$ promotes cell proliferation and inhibits apoptosis. During this process, CD14 has an indispensable role. The inhibition of CD14 expression blocks the transmission of the downstream signals of LPS, offsetting its activating effect. However, cell proliferation and apoptosis may be regulated by numerous signaling pathways. Downstream of the TLR4 signal, the interleukin-1 receptor-associated kinase 2, protein kinase-R, mitogen-activated protein kinases and other signaling pathways are located. In addition, TLR2 and TLR6 exhibit synergistic effects with CD14 via different signaling pathways to mediate the signaling transmission of LPS $(29,30)$. Therefore, further studies are required to define the mechanism of action of CD14 in the development of gastric cancer.

In conclusion, the present study reported a significant role for CD14 in the mediation of the LPS signal. Forced silencing of CD14 alleviated LPS-induced cell proliferation and increased levels of apoptosis in gastric cancer cells. In addition, upregulation of TNF- $\alpha$, IL-1 $\beta$, IL-6, IL-12, hBD-2 and activation of TLR4 by LPS was also inhibited by CD14 knockdown. The present study provides novel evidence regarding the pathogenesis of $H$. pylori.

\section{Acknowledgements}

The present study was supported in part by a grant from the National Natural Science Foundation of China (grant no. 81060165) and a grant from the National 'Twelfth Five-Year' Plan for Science \& Technology Support of China (grant no. 2013BAI05B04).

\section{References}

1. Jemal A, Bray F, Center MM, Ferlay J, Ward E and Forman D: Global cancer statistics. CA Cancer J Clin 61: 69-90, 2011.

2. Parkin DM: The global health burden of infection-associated cancers in the year 2002. Int J Cancer 118: 3030-3044, 2006.

3. Herrera V and Parsonnet J: Helicobacter pylori and gastric adenocarcinoma. Clin Microbiol Infect 15: 971-976, 2009.

4. Pugin J, Heumann ID, Tomasz A, et al: CD14 is a pattern recognition receptor. Immunity 1: 509-516, 1994.

5. Wright SD, Ramos RA, Tobias PS, Ulevitch RJ and Mathison JC: CD14, a receptor for complexes of lipopolysaccharide (LPS) and LPS binding protein. Science 249: 1431-1433, 1990.

6. Li K, Dan Z, Hu X, et al: CD14 overexpression upregulates TNF-alpha-mediated inflammatory responses and suppresses the malignancy of gastric carcinoma cells. Mol Cell Biochem 376: 137-143, 2013.

7. Gadducci A, Ferdeghini M, Castellani C, et al: Serum levels of tumor necrosis factor (TNF), soluble receptors for TNF (55- and 75-kDa sTNFr) and soluble CD14 (sCD14) in epithelial ovarian cancer. Gynecol Oncol 58: 184-188, 1995.

8. Kanczkowski W, Tymoszuk P, Ehrhart-Bornstein M, Wirth MP, Zacharowski $\mathrm{K}$ and Bornstein SR: Abrogation of TLR4 and CD14 expression and signaling in human adrenocortical tumors. J Clin Endocrinol Metab 95: E421-E429, 2010.

9. Li K, Dan Z, Hu X, Gesang L, Ze Y and Bianba Z: CD14 regulates gastric cancer cell epithelialmesenchymal transition and invasion in vitro. Oncol Rep 30: 2725-2732, 2013.

10. Peek RM Jr, Fiske C and Wilson KT: Role of innate immunity in Helicobacter pylori-induced gastric malignancy. Physiol Rev 90: 831-858, 2010. 
11. Polk DB and Peek RM Jr: Helicobacter pylori: gastric cancer and beyond. Nat Rev Cancer 10: 403-414, 2010.

12. Correa P and Piazuelo MB: Helicobacter pylori infection and gastric adenocarcinoma. US Gastroenterol Hepatol Rev 7: 59-64, 2011.

13. Blaser MJ and Kirschner D: The equilibria that allow bacterial persistence in human hosts. Nature 449: 843-849, 2007.

14. Schmausser B, Andrulis M, Endrich S, et al: Expression and subcellular distribution of toll-like receptors TLR4, TLR5 and TLR9 on the gastric epithelium in Helicobacter pylori infection. Clin Exp Immunol 136: 521-526, 2004.

15. Schmausser B, Andrulis M, Endrich S, Muller-Hermelink HK and Eck M: Toll-like receptors TLR4, TLR5 and TLR9 on gastric carcinoma cells: an implication for interaction with Helicobacter pylori. Int J Med Microbiol 295: 179-185, 2005.

16. Zhao D, Sun T, Zhang X, et al: Role of CD14 promoter polymorphisms in Helicobacter pylori infection-related gastric carcinoma. Clin Cancer Res 13: 2362-2368, 2007.

17. Grandel U, Banat A and Savai R: Effect of endotoxin on COX-2 dependent proliferation of NSCLC cells: Role of CD14, TLRs and EGFR signaling. J Clin Oncol (Meeting Abstracts): e22190, 2009.

18. Hattar K, Savai R, Subtil FS, et al: Endotoxin induces proliferation of NSCLC in vitro and in vivo: role of COX-2 and EGFR activation. Cancer Immunol Immunother 62: 309-320, 2013.

19. He W, Liu Q, Wang L, Chen W, Li N and Cao X: TLR4 signaling promotes immune escape of human lung cancer cells by inducing immunosuppressive cytokines and apoptosis resistance. Mo Immunol 44: 2850-2859, 2007.

20. ChanKL,WongKFandLukJM:RoleofLPS/CD14/TLR4-mediated inflammation in necrotizing enterocolitis: pathogenesis and therapeutic implications. World J Gastroenterol 15: 4745-4752, 2009.
21. Baumann CL, Aspalter IM, Sharif O, et al: CD14 is a coreceptor of Toll-like receptors 7 and 9. J Exp Med 207: 2689-2701, 2010.

22. Wang JH, Manning BJ, Wu QD, Blankson S, Bouchier-Hayes D and Redmond HP: Endotoxin/lipopolysaccharide activates NF-kappaB and enhances tumor cell adhesion and invasion through a beta 1 integrin-dependent mechanism. J Immunol 170: 795-804, 2003.

23. Molteni M, Marabella D, Orlandi C and Rossetti C: Melanoma cell lines are responsive in vitro to lipopolysaccharide and express TLR-4. Cancer Lett 235: 75-83, 2006.

24. Kelly MG, Alvero AB, Chen R, et al: TLR-4 signaling promotes tumor growth and paclitaxel chemoresistance in ovarian cancer. Cancer Res 66: 3859-3868, 2006.

25. Bauer B, Wex T, Kuester D, Meyer T and Malfertheiner P: Differential expression of human beta defensin 2 and 3 in gastric mucosa of Helicobacter pylori-infected individuals. Helicobacter 18: 6-12, 2013.

26. Moran AP: The role of endotoxin in infection: Helicobacter pylori and Campylobacter jejuni. Subcell Biochem 53: 209-240, 2010.

27. Xie C, Kang J, Li Z, et al: The açaí flavonoid velutin is a potent anti-inflammatory agent: blockade of LPS-mediated TNF-alpha and IL-6 production through inhibiting NF-kappaB activation and MAPK pathway. J Nutr Biochem 23: 1184-1191, 2012.

28. Dolcet X, Llobet D, Pallares J and Matias-Guiu X: NF-kB in development and progression of human cancer. Virchows Arch 446: 475-482, 2005.

29. Akira S and Takeda K: Toll-like receptor signalling. Nat Rev Immunol 4: 499-511, 2004.

30. Underhill DM and Ozinsky A: Toll-like receptors: key mediators of microbe detection. Curr Opin Immunol 14: 103-110, 2002. 